\title{
Agosto, de Rubem Fonseca, y el Varguismo en BrasiL*
}

\section{Gustavo Forero Quintero**}

\section{Resumen}

La novela de crímenes Agosto (1990), de Rubem Fonseca, plantea la reescritura de una parte de la historia brasilera: el último gobierno de Getulio Vargas (1951-1954). A partir de la teoría de la anomia, este trabajo busca explicar los efectos ideológicos del modo en que el escritor resuelve la confusión vivida por el héroe, el comisario Alberto Mattos, en una situación de ausencia de ley o pérdida de la vigencia de la misma. Lejos de proponer una lectura liberal y antimarxista de la historia, como esgrimen en su contra los críticos de la novela, se puede afirmar que en Agosto Rubem Fonseca da cuenta del continuismo de las políticas getulistas en la política brasilera contemporánea. Desde su punto de vista, pese a las supuestas transformaciones democráticas en el país persiste un Varguismo sin Vargas.

Palabras clave: Novela de crímenes, anomia, Getúlio Vargas, Rubem Fonseca.

\section{Agosto, by Ruben Fonseca, And the Vargasism in BRAZIL}

\begin{abstract}
The crime novel Agosto (1990) by Rubem Fonseca presents a rewriting of part of Brazilian history: the last government of Getulio Vargas (1951-1954). Based on the theory of anomie, this article aims to explain the ideological effects of the way the writer resolves the confusion experienced by the hero, inspector Alberto Mattos, in a situation in which the law is absent or in which the validity of that law has been lost. Without proposing a liberal and antiMarxist reading, as critics of the novel have accused it of containing, we can maintain that in Agosto, Rubem Fonseca gives an account of the continuing nature of Getulist policies in contemporary Brazilian politics. From his point of view, despite the supposed democratic transformations that have taken place in the country, the presence of Vargasism persists even without Vargas.
\end{abstract}

Keywords: Roman Noir, Thriller, anomie, Getúlio Vargas, Rubem Fonseca.

Recibido: 24-01-2014

Aceptado: 23-08-2014

* Este trabajo forma parte del Proyecto de investigación La novela de crímenes en Iberoamérica, financiado por la Universidad de Antioquia, Colombia, a través del Comité para el Desarrollo de la Investigación, CODI. También, fue posible gracias al apoyo del Programa de la Estrategia de Sostenibilidad del Grupo Estudios Literarios, GEL, 2013-2014, al cual pertenece el autor.

** Colombiano, Abogado, Licenciado en Letras, Magíster en Études Romanes de la Universidad de la Sorbona y Doctor Cum Laude en Literatura Española e Hispanoamericana de la Universidad de Salamanca. Académico de la Universidad de Antioquia, gustavo.forero@udea.edu.co 
Agosto, de Rubem Fonseca, y el Varguismo en Brasil / Gustavo Forero

"En toda autoridad hay, de cierto modo, algo corrupto e inmoral"

(Fonseca 346).

La novela de crímenes Agosto (1990), de Rubem Fonseca (Juiz de Fora, Minas Gerais 1925), recrea lo ocurrido en un momento estelar de la historia de Brasil: el pretendido golpe de Estado de las fuerzas militares en 1954 y el consecuente suicidio del presidente electo para la época, Getúlio Vargas (1882-1954). Así, en un término de 24 días del mes de Agosto, que inspiran el número de capítulos de la novela y su título, la investigación del asesinato del empresario Paulo Gomes Aguiar revela un ambiente de corrupción y anomia estatal, acrecentado por el enfrentamiento que se desata tras el atentado del opositor Carlos Lacerda entre el Gobierno del líder populista y la cúpula militar. En este artículo se plantea un análisis de la novela desde la teoría de la anomia social, es decir, a partir del estudio de los efectos de la situación de ausencia de ley o pérdida de la vigencia de la misma que en un momento dado acusa el mundo épico en la literatura y que provoca la confusión moral de un personaje. ${ }^{1}$ Bajo tal supuesto, se puede afirmar que lejos de proponer una lectura liberal y antimarxista de la historia, como esgrimen en su contra los críticos de la novela, el modo en que se resuelve el conflicto permite afirmar que en Agosto Rubem Fonseca da cuenta de la persistencia del Varguismo sin Vargas en la política brasilera contemporánea. Así lo podemos concluir a partir de tres apartados que aluden a la naturaleza de la investigación que realiza el comisario Alberto Mattos en la novela; el perfil del personaje como alter ego del escritor; la crítica literaria en torno suyo y el estudio de algunos elementos concretos de la historia del Brasil como la creación de la empresa Eletrobrás y la carta testamento de Getulio Vargas que se recrean en novela, según se verá a continuación.

\section{La investigación ficticia e histórica: el conflicto privado y el conflicto político}

En Agosto, la recreación literaria del atentado contra el periodista Carlos Federico Werneck de Lacerda, llamado "El Cuervo", se une

1 La teoría está planteada en mi libro La anomia en la novela de crímenes en Colombia (Siglo del Hombre, 2012).

$+100$


al hecho ficticio del asesinato del empresario Paulo Gomes Aguiar, perpetrado por motivos económicos. El vínculo entre ambos hechos es Gregório Fortunato, Jefe de la Guardia Personal del Presidente, sobre quien recae la sospecha inicial del comisario Alberto Mattos por el asesinato del empresario. Este hombre es inocente del cargo, mas no del atentado: es él quien lo planea junto con Climério Euripedes de Almeida, su colega (392), por mandato de Euvaldo Lodi, diputado general. Así, la narración paralela de ambos eventos le permite a Fonseca revelar desde un hecho privado la profunda crisis moral de los estamentos públicos brasileros.

En primer lugar, la investigación de Mattos llega a establecer a lo largo de la novela que el homicidio de Gomes lo cometen su esposa y Pedro Lomagno, su amante, por los réditos que dejará a la empresa una intriga financiera urdida por el mismo Fortunato y otros miembros del Gobierno, entre quienes se encuentra el senador Vitor Freitas ${ }^{2}$. Sin embargo, la investigación de este asesinato cede su importancia a la recreación literaria de los hechos históricos: tras el atentado de Lacerda, en el que resulta muerto su guardaespaldas, el aviador Vaz, se desata una reacción radical de un ala de las fuerzas armadas en contra del gobierno que trae como consecuencia el caos general y, finalmente, el suicidio del Presidente. El propio Lacerda, inspirado, quizás, por el "manifiesto golpista y reaccionario" (Fonseca 11) que el Ministro de Guerra y algunos militares habían divulgado en febrero de ese mismo año, promueve la crisis gubernamental al responsabilizar al propio Vargas de los hechos: “-Responsabilizo al Presidente de la República del atentado. ... Fue la impunidad del gobierno la que armó el brazo criminal" (104). La crisis nacional se acrecienta hasta el punto de que miembros del Senado llegan a afirmar, junto con los militares, que Getúlio tiene los días contados (132). Así afirma el propio Vitor Freitas:

El atentado cambió todo. ... Los militares están furiosos con la muerte del mayor Vaz. Hoy será realizada una asamblea

2 Gomes fue favorecido por el senador Vitor Freitas, que le proporcionó los medios necesarios para el desarrollo de la empresa Cemtex. Esta situación lleva a que su esposa y Pedro Lomagno, su amante, ordenen su asesinato para favorecerse de la prebenda. Para ello contratan a Chicão, amigo de Lomagno, que no obstante su habilidad para el crimen deja un pelo y un anillo de oro en el lugar de los hechos. Una F grabada en este último desvía la atención del comisario hacia Gregorio Fortunato, que se revela como inocente de este hecho al final del relato. La investigación de la guardia presidencial, no obstante, le permite al comisario ser un espectador directo de la crisis nacional sufrida en agosto de 1954. 
Agosto, de Rubem Fonseca, y el Varguismo en Brasil / Gustavo Forero

en el club de Aviación con objetivos nítidamente golpistas. ... La verdad es que los ministros militares ya no tienen ningún control sobre la oficialidad joven. Cuando los generales sólo consiguen mandar a otros generales la cosa va mal. Muy mal (135-136).

De este modo, en un paralelo lúcido del oportunismo político de Lacerda, que contó antes con el favor del Presidente y luego encarna la oposición, advierte también el senador Freitas:

Dar a un hombre con aquella terrible elocuencia algún poder, por exiguo que fuese, era muy peligroso. Habría sido mejor que Lacerda hubiera sido asesinado y no su guardaespaldas. Getúlio Vargas, con su anticuada oratoria monótona y prudente, había conseguido dominar al país durante tanto tiempo; ¿qué no haría Lacerda con su inteligencia incendiaria y su capacidad de usar las palabras, como ningún otro político en la historia de Brasil, para persuadir, engañar, emocionar, movilizar a las masas? Sus artículos en el periódico y sus alocuciones por radio, en los últimos días, habían obligado al gobierno a acuartelar de emergencia a treinta mil soldados, sólo en Rio de Janeiro (215).

Así, como consecuencia de la intriga política de Lacerda: "Dos corrientes facciosas y antagónicas se enfrentaban" (217). El presidente Getúlio Vargas pierde el apoyo de una importante franja de los militares y queda a merced de algunos de ellos apoyados por diversos sectores sociales -entre quienes participan "la Iglesia, sectores de las Fuerzas Armadas, sectores del mundo empresarial, partidos políticos de la oposición y la prensa" (212) — que quieren su caída. El Ejército dividido como consecuencia del atentado contra Lacerda pone a tambalear la democracia y esto hace que el presidente Getúlio busque salidas, entre las que llega en principio a considerar su renuncia, "para evitar una guerra civil" (225). Sin embargo, con el paso de los días la crisis se acrecienta, presentándose tal situación anómica (revela el vacío de poder que sufre el sistema) que algunos llegan a afirmar que "solamente las Fuerzas Armadas podían salvar el país" (276). En tal contexto, en una de las poquísimas veces que interviene directamente en la novela, el presidente Getúlio Vargas dice como un Salvador Allende: “-No renunciaré. Fui elegido por el pueblo y las Fuerzas Armadas no pueden desalojarme.

$+102$


De aquí sólo salgo muerto" (425), insinuando el final histórico de los hechos $^{3}$. El narrador señala que solo personas como el líder portuario Duque de Assis se solidarizan con Vargas:

Una de las pocas voces discordantes en el coro de invectivas contra Vargas fue la del líder de los portuarios, Duque de Assis. En su opinión, el movimiento por la renuncia de Vargas tenía como objetivo único impedir el progreso del país y obstaculizar el avance del movimiento obrero. "Nuestros opositores del gobierno y del proletariado están a sueldo de fuerzas ocultas", dijo el portuario (398).

Los acontecimientos se resuelven finalmente con el suicidio del presidente Getulio Vargas (445 y ss.) y el asesinato del investigador Alberto Mattos, que confirman el ambiente de anomia reinante en la novela pues no se restablece ningún orden en la historia, como sucedería en una novela clásica detectivesca y como lo plantea Siegfried Kracauer al hablar de la ratio moderna: las Fuerzas Armadas aprovechan la situación agregando una nota a su famosa Carta Testamento; y, aunque el principal sospechoso del crimen del industrial Paulo Gomes Aguiar es el jefe de la Guardia personal del Presidente, el comisario y su amante Salete son asesinados por Chicão, el autor material del crimen de Gomes, quien garantiza así su impunidad y la de los autores intelectuales del asesinato. En un ambiente de corrupción generalizada ("-Todos los de esta mesa somos unos hijos de puta corruptos. Todos los de este país" [137], advierte en un momento dado Vitor Freitas), Fonseca evalúa así los acontecimientos que llevan a la muerte de Getúlio Vargas, caracterizados

3 Agosto podría compararse con Quem matou Vargas (1967), de Carlos Heitor Cony, donde se habla de un suicidio político derivado de la acción de Estados Unidos a propósito del petróleo brasilero; O homem que matou Getúlio Vargas: Biografia de um anarquista (1998), de Jô Soares, donde se recrea la concurrencia simbólica de dos voluntades en la acción suicida del presidente -el "dedo que suicida", según la novela (332)—; Getúlio (2004), de Juremir Machado da Silva, que también hace alusión a las circunstancias que rodearon el suicidio de Vargas, y O dia em que Getúlio matou Allende: e outras novelas do poder (2011), de Flavio Tavares, donde se plantea el suicidio de Allende como consecuencia del ejemplo de Vargas de una oposición digna frente a la voluntad golpista de las fuerzas armadas. Como señala Tatiana Zismann, "o suicídio do presidente Vargas será uma frontera fácilmente transposta para uma interpretacao causal homicida no campo ficcional" (170). La relación entre la historia y la ficción ha sido estudiada por Karl Eric Schollhammer, quien inscribe a Agosto dentro de la "historiografía metaficcional posmoderna" junto con Tocaia Grande (1984), de Jorge Amado, y Viva o povo brasileiro (1984), de João Ubaldo Ribeiro, que también realizan un ejercicio de ficcionalización de la historia; por Osmar Pereira Oliva, quien habla de esta clase de literatura como muestra del "entrecruzamento da ficção e da História na composição do texto literários" (69) y en tal sentido propone a Agosto como ejemplo del "discurso marginal fonsequiano", y por Thomas Waldemer, que estudia la novela como fruto de la "dichotomy of the ephemeral and the historical" (33), es decir, de lo histórico con lo anecdótico con preeminencia de la historia de un personaje anónimo. 
ante todo por la confusión moral que encarna el personaje principal frente al contexto político que lo rodea. Al final, a pesar de la muerte de Mattos y Vargas las cosas siguen igual que antes: el Estado responde a las manifestaciones con represión y el crimen de Mattos queda impune, pero: "La ciudad tuvo un día tranquilo" (480). Desde este punto de vista se pueden analizar las características del comisario como héroe de la novela y su relación con el autor como alter ego suyo.

\section{El comisario Alberto Mattos como alter ego de Fonseca y la confusión moral}

La biografía del escritor Rubem Fonseca es fundamental a la hora de evaluar la confusión moral que atraviesa el personaje Alberto Mattos, inmerso en ese contexto de crisis política y anomia social. Al igual que Mattos, el escritor fue abogado especializado en Derecho Penal y en tal calidad ingresó a la Academia de Policía de Rio de Janeiro en 1949, donde obtuvo su ascenso a comisario en el $16^{\circ}$ Distrito Policial, en São Cristóvão, cuando el presidente Vargas firmó el Acuerdo de Asistencia Militar entre Brasil y los Estados Unidos (1952). Asimismo, como el personaje Mattos -el "Cráneo" de la Facultad, según Padua, su colega (401)_, durante el mandato de Vargas el escritor fue alumno brillante de la Escuela de Policía, tanto así que recibió una beca para estudiar Criminología en Estados Unidos con el propósito de que después impartiera clases en la Fundación Getúlio Vargas, en Rio de Janeiro. De aquí surgió su pasión por ese país, su conocimiento directo de la obra de escritores como Dashiell Hammett y Raymond Chandler, que determinarían su interés por el género, y, sobre todo, sus eventuales contactos ideológicos con Estados Unidos (como lo expone Alinne Andrade Pereira): luego de la muerte de Vargas, entre 1956 y 1957, Fonseca realizó, además, cursos de verano sobre Administración en la Universidad de Boston que habrían de servirle en su posterior desempeño profesional como relacionista público en la empresa privada (Petrick, párr. 11). En tal sentido, el escritor brasilero mantuvo su cargo en la Policía hasta su exoneración el 6 de febrero de 1958, lo que demuestra su alejamiento del campo oficial, y aunque intentó conseguir un puesto como juez en la misma administración pública prefirió continuar su carrera como ejecutivo especializado en el área de propaganda y relaciones públicas realizando una serie de actividades que incidirían directamente tanto en su futuro laboral como en su producción literaria.

-


De acuerdo con lo anterior, como señala Ariovaldo José Vidal, se puede advertir que Agosto "é um libro que anda pelo passado do escritor, o que deve denunciar o problema mal resolvido e mal contado de suas ligações com o poder" (6). Efectivamente, la novela Agosto puede tomarse como una recreación del pasado del escritor como comisario de la Policía en la época getulista y, a posteriori, como una explicación de la transformación en su perspectiva ideológica respecto de la misma. Sus estrechos vínculos con ciertos líderes del poder político en el país luego de su contacto con Estados Unidos pueden explicar esta transformación. Hasta cierto punto, puede afirmarse que el abogado y comisario de policía Alberto Mattos, protagonista de la novela, es un alter ego de Fonseca que reflexiona lúcidamente en sus circunstancias personales en la época de decadencia de Vargas, es decir, en el año 1954. Como señala Jayro Luna:

Os primeiros fatos da obra Agosto são reais (crime da Rua Toneleros e o suicídio de Vargas). Contudo, o principal personagem, o Comissário Mattos, é fictício. O Comissário, na verdade, é o 'alter ego' do autor .... A obra é narrada, em terceira pessoa, do ponto de vista do ingênuo, porém inteligentíssimo, Comissário. [O autor] não tece críticas à situação da época; ele, simplesmente, narra os fatos do ponto de vista de alguém correto, vítima de brutalidades políticas e de corrupção policial. O autor entra na história que mancha o país e, por isso, cria este 'outro eu' para atingir seu objetivo. Visando dar conotação fictícia à história que envolveu fatos reais, Fonseca cria outros personagens, justamente para dar vida ao seu 'alter ego' (párr. 21).

De tal manera, alrededor de esa presunta "mancha" histórica que puede ser la historia de Getúlio Vargas desde la perspectiva de 1990, cuando se publica la novela, se pueden comparar las acciones del personaje, el comisario Alberto Mattos, y el autor, Rubem Fonseca: mientras Mattos es un comisario depresivo, atormentado por una úlcera gástrica y por el amor de dos mujeres, Alicia y Salete, que parte de cierta confianza en el sistema para hundirse en una verdadera confusión política con un hálito existencialista y romántico ${ }^{4}$, Fonseca puede definirse como un abogado

4 El epígrafe de la novela del Ulysses, de James Joyce, así puede confirmarlo: "History, Stephen said, is a nightmare from which I am trying to awake". Al respecto, resulta interesante el acercamiento a la obra de Hugo Chaparro Valderrama (2002) que establece la relación entre la descomposición social y la corrupción individual. 
sagaz con intereses muy precisos tanto en el campo del éxito profesional como económico. Según Clemens Franken:

Se trata, así, en la obra literaria de Rubem Fonseca, de un mundo totalmente podrido, un caos sin Dios, leyes ni normas. En esta visión de mundo, bastante nietzscheana, existencialista y atea, al hombre no le queda más que asumir una actitud desencantadora y cínica, dado que supuestamente no existe el más mínimo espacio para la esperanza y los ideales (117).

Así, la mirada crítica de Mattos, que en 1954 "Tuvo deseos de estrellar el libro [de derecho civil] contra la pared" (35), se diferencia de la perspectiva pragmática del Fonseca relacionista público que empieza a defender los intereses económicos del sector privado y a encontrar un espacio privilegiado en él. Desde esta segunda perspectiva se debe advertir que, luego del revés en la administración judicial, el escritor obtiene un puesto en Light, la mayor empresa privada dedicada a la explotación de la energía eléctrica en Brasil. Por su parte, mientras Mattos puede tomarse como un getulista y más tarde como un personaje confundido en su opción política, en los años siguientes a su labor en la administración de Justicia Fonseca se distancia bastante del líder populista y se vincula con el liberalismo antimarxista que representa la propia empresa en la cual trabaja. De esta manera, persisten los acercamientos entre el personaje y creador como consecuencia de su ideología. Así, mientras para el investigador de la novela, Mattos, existen notorias diferencias entre la dictadura inicial de Getúlio Vargas -que rechaza en su momento y por la que es apresado en 1944- y la democracia del año 1954, que él mismo encarna como comisario federal con anhelos de justicia, el escritor sigue su propia ruta hasta el liberalismo. Hasta cierto punto el personaje defiende la democracia getulista, pues, según revela su ficha policial (347) de 1945 (cuando es aprehendido como "queremista"5) a 1954 (cuando revela sus dudas respecto del sistema) hay cierta transformación: la contraposición de estos dos momentos históricos le permite afirmar, en primer lugar, que si Vargas empezó como dictador, se transformó pronto

5 Mattos hizo parte del movimiento político queremista que surgió en mayo de ese año a partir del slogan "Queremos Getúlio", difundido en apoyo al presidente que había sido destituido por quienes se oponían a las transformaciones democráticas. Este movimiento implicaba el aplazamiento de las elecciones presidenciales, el lanzamiento de la nueva candidatura de Vargas a la presidencia y la convocatoria de la Asamblea Nacional Constituyente. Hasta cierto punto, este movimiento logró su objetivo, pues se promulgó la Constitución de 1946 (elaborada, no obstante, bajo la presidencia posterior de Eurico Gaspar Dutra, elegido el 2 de diciembre de 1945 para suceder a Vargas).

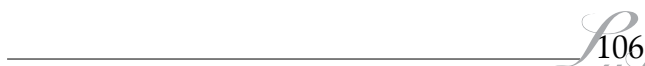


en un demócrata gracias al apoyo popular; pero, en segundo lugar, que a pesar de Vargas el sistema sigue marchando por los viejos caminos de la política tradicional y que al parecer así continuará sucediendo por un buen tiempo (juicio que constituye la médula de la perspectiva del escritor que es rechazada por sus críticos). Por esta razón, al definir lo que es un buen policía y la naturaleza de la autoridad, Mattos afirma:

- Para mí todos los crímenes son iguales. Soy un policía. ... A nosotros, los policías, no nos compete hacer juicios de valor sobre un hecho ilícito. ... Aquellos que se consideran hombres de bien no siempre son buenos policías -Pausa-. El mejor policía sería tal vez un autómata que conociera bien la ley y la obedeciera ciegamente. ... En toda autoridad hay, de cierto modo, algo corrupto e inmoral (346).

Esta fe y a la vez desengaño respecto de la función policiva y de lo que es la autoridad es lo que en efecto define los pasos del personaje y lo acerca a la perspectiva individual de su creador sobre el Varguismo como política que perdura en Brasil. Mattos, que no es el héroe ingenuo al que se refería Jayro Luna, reconoce el progreso del sistema pero duda del papel de la autoridad policiva, pues el mundo ideal en el que quiere creer choca con la realidad que le toca vivir: "El mundo en el que vivía era una mierda. El mundo entero era una mierda" (365), afirma como un típico detective de novela negra y muy cercano al individualismo de su creador. Por tal razón, como comisario idealista llega a apoyar una huelga carcelaria por las circunstancias en que se encuentran los presos que él vigila, y en un momento dado le dice a un recluso: "Usted no debería estar aquí, ninguno de ustedes debería estar aquí, pero yo no puedo hacer nada" (44). Y luego, cuando su asistente Rosalvo lo inquiere respecto de su filiación política, responde de esta manera:

- ¿Le puedo hacer una pregunta?

- Sí -respondió el comisario.

- En definitiva, ¿el señor es lacerdista o getulista?

- ¿Tengo que ser alguna de esas dos mierdas? (46).

La cuestión tiene qué ver fundamentalmente con la teoría y la práctica de una ideología. Conforme al getulismo populista de la época (el que recibe la carta de apoyo de los presos comunistas en 1943), cada mañana, cuando asume el servicio policial, Mattos deja salir a las personas 
aprehendidas la noche anterior por su colega Padua. Aunque esta decisión vaya contra el régimen legal, para Mattos resulta una acción lógica y necesaria dada la gravedad de la situación que viven los prisioneros. La lucha por la defensa de los derechos de los reclusos se identifica entonces con la teoría que ha expuesto Vargas, es decir, con el indulto populista que pretendió el Presidente en un momento dado, según la misma novela, y que se opone a la realidad carcelaria, como puede percibirse de nuevo en esta conversación entre Mattos y su asistente Rosalvo:

- ¿Vio que el presidente va a indultar más delincuentes? Ya en julio fueron beneficiados treinta asesinos, veintidós ladrones, tres estafadores, un macumbeiro y un encubridor. ¿Qué piensa de todo esto, doctor? ¿Más de setenta delincuentes puestos en libertad?

-Ni siquiera han debido ser detenidos. ... Encarcelar a un macumbeiro, a un encubridor, es una estupidez. Un preso le cuesta un dineral a la sociedad, permanece un tiempo en la cárcel y sale peor de lo que entró (281).

En tal sentido, resulta apenas obvio que, casi al final del libro, Mattos exprese su confusión a propósito del primer y el último Vargas, y en general respecto de su gobierno: "Getúlio Vargas hace parte de mi vida. ... Me duele Getúlio. Sé que esto parece absurdo; yo mismo estoy sorprendido. ... En aquella época yo andaba muy confundido. ... Ahora también" (430-431). Esta perspectiva de la confusión del comisario respecto de un momento anómico de la época getulista se suma a la perspectiva del continuismo político que sugiere la resolución de la novela y que se analizará a continuación. Si la ausencia de legitimidad en un momento dado produce confusión en el investigador, el suicidio del Presidente constituye la materia prima que utiliza el escritor para demostrar las razones de su propia transformación ideológica luego de haber podido ser el getulista de los años cincuenta cuando trabajaba como Comisario federal. Tal como propone buena parte de la crítica literaria en el Brasil, Rubem Fonseca cambia ideológicamente durante estos años: de cierto getulismo hacia su visión liberal. Su perspectiva ideológica se manifiesta entonces alterando el relato histórico para hacerlo coincidir con sus propios intereses personales. En tal sentido, su vinculación con la empresa Light y con algunos sectores políticos antimarxistas resulta de gran importancia para entender su obra. 


\section{La crítica literaria: en torno a Light y Eletrobrás}

El antropólogo Darcy Ribeiro, Ministro de Educación del presidente João Gulart (quien justamente fuera derrocado en el golpe de 1964) y uno de los fundadores del Partido Democrático Trabalhista (PDT) en 1980 y de la Universidad Nacional de Brasilia, UNB, afirma:

O romance Agosto é o último gesto de servidão de Rubem Fonseca a seu amo Gallotti, o testa-de-fero da Light. Não esclarece o único ponto decisivo do drama sobre o qual devia e podia depor que seria nos dizer a quem interessava a deposição de Getúlio Vargas. Não há dúvida que a grande interessada era Light para impedir que Getúlio consumasse a criação da Eletrobrás. Jango achava que foi a Light que patrocinou a campanha de difamação e armou a trama que resultou no suicídio. Seria apenas ridícula se não fosse afrontosa sua atribuição da autoria da Carta Testamento a um oficial da Aeronáutica. A Carta que é o mais alto documento da história brasileira é também magistralmente escrita (261).

Según este crítico, en medio del contexto político de la pos dictadura (luego de 1985), la resolución de la novela Agosto demuestra la ideología liberal del escritor y, más aún, su probable cohonestación con los responsables de la dictadura que se impuso en Brasil en 1964 y que, aunado al Plan Cóndor 6 , significó el apoyo de los Estados Unidos a otros golpes militares en América Latina. Desde su punto de vista, la vinculación de Fonseca con la empresa Light y su amistad con Antonio Gallotti, presidente de esta compañía y fundador del Instituto de Pesquisas e Estudos Sociais, Ipês, en 1962, así lo confirmarían. Este último organismo tenía como objetivo diseminar un pensamiento liberal y antimarxista en el país y estuvo involucrado en el golpe de Estado al presidente João Goulart en 1964. Al respecto, también Alinne Andrade advierte la desafortunada relación que existió durante la época entre el escritor y esta línea política reaccionaria encarnada en Ipês:

6 Con este nombre se conoce el plan desarrollado durante las décadas de 1970 y 1980 entre varios gobiernos suramericanos y la CIA de los Estados Unidos con el propósito de reprimir, por medio de seguimiento, detención, interrogación, traslado e incluso desaparición o asesinato, a aquellas personas consideradas subversivas o contrarias a los regímenes dictatoriales reinantes en Chile, Argentina, Brasil, Paraguay, Uruguay, Bolivia y esporádicamente, Perú, Colombia, Venezuela y Ecuador. Generalmente las víctimas pertenecían a grupos disidentes, casi siempre adscritos a la izquierda política. 
Rubem Fonseca participava de todas as reuniões. Há transcrições de opiniões dele, com assinatura na ata, em geral no cargo de 'secretário'. Não encontrei provas definitivas, mas várias pessoas afirmaram que ele era o autor dos roteiros dos filmes publicitários do Ipês (cit. en Petrik, párr. 15).

Desde este punto de vista, para Ribeiro y Andrade, a Fonseca no le interesaba esclarecer en su novela Agosto el móvil real del suicidio de Vargas: el interés de Light en evitar la consolidación de Eletrobrás (Agencia Nacional de Energía Eléctrica, ANEL). Si Fonseca había trabajado con Gallotti y al servicio de Ipês no podía revelar en su novela esta cuestión como causa directa del suicidio de Vargas. Desde el punto de vista de estos críticos, justamente el presidente "Jango", o João Gulart, había señalado hacía años que la empresa Light patrocinó la campaña de difamación de Vargas y armó toda la trama que lo llevó a su inmolación. Dada su trayectoria y su personalidad, Getúlio jamás hubiera aceptado algo como la privatización del sector energético y, por lo tanto, el monopolio de Light. De hecho, en su Carta Testamento Vargas afirma: "Quis criar liberdade nacional na potencialização das nossas riquezas através da Petrobrás e, mal começa esta a funcionar, a onda de agitação se avoluma. A Eletrobrás foi obstaculada até o desespero. Não querem que o trabalhador seja livre" (Baun 227).

De la misma manera, como Darcy y Andrade, los críticos Tiago Petrik, Malu Porto y João Gabriel de Lima subrayan el hecho de que Fonseca trabajó en el departamento de relaciones públicas de Light, pero, sobre todo, fue reclutado como secretario y publicista del Ipês, circunstancia que determinó su visión de la historia e, incluso, aseguró posteriormente su éxito literario, incluido el de la novela Agosto. Para apoyar esta perspectiva, también Mariana Bittencourt Faraco señala que en un momento dado Fonseca fue asesor del general Golbery do Couto e Silva (24), ${ }^{7}$ otro de los fundadores del Ipês en 1962, quien gracias a las condiciones ideológicas de Fonseca, es decir, a su presunta filiación liberal y su rechazo al comunismo, propició su futuro profesional en el campo de la literatura: según ella, el editor Gumercindo Rocha Dorea,

7 Profesor de la Escola Superior de Guerra dirigida por el general Juárez Távora. Contó con el apoyo del general Humberto de Alencar Castelo Branco. Fue Jefe de Gabinete de la Presidencia de la República (1974-1981) de Ernesto Geisel y Ministro de Planeamiento y Ministro de Justicia durante la presidencia de João Baptista Figueiredo (1979-1985). En 1966 resumió su pensamiento en el libro Geopolítica do Brasil.

110


amigo de aquel, le sirvió efectivamente al escritor para fortalecer su carrera literaria. En tal sentido Petrik, Porto y de Lima afirman que:

Essa época é relevante na vida do escritor também por outra razão. Foi em parte graças à convivência com a turma que se opunha ao presidente -e mais tarde ajudaria a articular o golpe militar de 1964- que José Rubem publicou seu primeiro livro de contos, Os Prisioneiros (párr. 13).

Y, por si esto fuera poco, los críticos afirman que en 1979, en plena época de dictadura, con João Baptista de Oliveira Figueiredo como presidente militar, el escritor fue invitado por Antonio Gallotti para participar de la administración municipal de Rio de Janeiro, durante la gestión del "prefeito biónico" (alcalde escogido por el gobierno militar) Israel Klabin, otro ex-integrante del Ipês, de reconocida filiación liberal. Así, confirmando el juicio de Ribeiro y Andrade, tales autores señalan:

A frase, proferida pelo antropólogo Darcy Ribeiro nos anos 90, referindo-se ao presidente da então maior empresa privada do país, dá a exata medida do patrulhamento ideológico sofrido pelo escritor por causa de suas posições políticas. Num país em que $90 \%$ dos intelectuais e escritores se definem como de esquerda, o autor de Agosto sempre se apresentou como um liberal. Como liberal, jogou no lado contrário dos marxistas durante o período mais polarizado da história política brasileira -o início dos anos 60, a época em que João Goulart ocupou a Presidência da República (párr. 13).

Al respecto, más tarde Petrik, Porto y de Lima agregan:

Qual a relevância da atividade política de José Rubem para a sua obra, além de lhe fornecer contatos para publicar o primeiro livro? Pode-se dizer que as crenças políticas do escritor evitaram que sua ficção sofresse, como a de tantos autores, a influência do marxismo -e isso pode ter sido bom. Seus personagens vivem numa realidade mais complexa do que aquela de que o conceito de 'luta de classes' tenta dar conta (párr. 19).

En efecto, en la novela analizada el escritor no da cuenta de una lucha de clases, ni le interesa hacerlo: Agosto se mantiene al margen de una resolución por la vía marxista de explicar al personaje por su carácter de 
ilustración de un conflicto social que al final se salda con el avance del proletariado. Por el contrario, la confusión de Alberto Mattos frente a su contexto histórico y la visión desesperanzada del sistema por parte del autor son solo parte de una descripción del continuismo de la política brasilera.

No obstante lo anterior, lo más grave de la novela, para los críticos, no es la filiación política del escritor que esto puede revelar, sino su ataque a una de las instituciones respetadas de la historiografía nacional que sustenta la protección de Vargas a los recursos naturales en el país. Desde la perspectiva de Darcy Ribeiro la atribución de Fonseca de la Carta Testamento de Vargas a un oficial de la Aeronáutica del Brasil difiere radicalmente del discurso histórico en perjuicio del Vargas progresista. El problema de la autoría de la carta es lo que está en el centro de la crítica literaria relativa a Agosto de Rubem Fonseca. Si hoy existen posiciones antagónicas respecto del valor de esta Carta Testamento, para el crítico es claro que conforme a los hallazgos de la historia oficial los dos textos difundidos de esta (mencionados también en la novela) provienen del mismo Vargas o, en su defecto, de Maciel Filho, periodista asesor encargado con frecuencia de los discursos del presidente, y en ningún caso de un miembro de las Fuerzas Armadas. Aunque existen ambas versiones de la Carta - una, mecanografiada, de la que se da cuenta en la novela antes de la muerte de Vargas (447), y una nota manuscrita que Fonseca le atribuye al mayor Fitipaldi (455), asesor militar del presidente (58-59) — , ninguna admite duda respecto de su autoría. La primera, de la que hay tres copias, se le atribuyó a Filho, pero esta versión fue desmentida por él mismo cuando le aseguró a la familia del presidente que él había ayudado a Vargas solo con la transcripción. Esta copia fue distribuida a la prensa como legado político de Vargas y fue en buena parte la razón para moderar el clima político posterior y evitar un golpe militar elevando a héroe y mártir nacional al presidente fallecido. La segunda, mucho más concisa, fue dada a conocer posteriormente como muestra de la autenticidad de la primera. En la novela esta última carta se atribuye al mayor Fitipaldi -quien, según Fonseca, "al conocer el suicidio del presidente, se había encerrado en una sala de la casa militar, en la planta baja, donde había escrito apresuradamente una nota al final de la cual había firmado con el nombre de Getúlio Vargas" (455)— y se entrega esa misma noche a los periodistas para confirmar el deceso del Presidente.

112


La controversia sobre la legitimidad del segundo texto, que en opinión de Darcy Ribeiro plantea Fonseca, altera gravemente la historia brasilera. Mucho más si se tiene en cuenta la cuestión de Eletrobrás que aclaró Vargas en uno de sus apartados, según se anotó antes. Aunque Fonseca parece ceñirse a la realidad histórica, la adjudicación de la autoría de la segunda nota manuscrita a Fitipaldi -“"Dejo a la saña de mis enemigos el legado de mi muerte', comenzaba la nota, que terminaba diciendo: 'La respuesta del pueblo vendrá más tarde'” (455) — legitima justamente a quienes estaban interesados en el derrocamiento de Vargas y buscaban el golpe de Estado: los militares, que reclamaban su renuncia o amenazaban, en su defecto, con su deposición por un golpe. De este modo, paradójicamente, las fuerzas armadas, que habían utilizado la muerte del mayor Vaz en medio del atentado a Lacerda como un pretexto para oponerse a las reformas democráticas, surgen como las garantes mismas de la democracia conseguida en el Estado Novo. La identificación del narrador con el sentido común de los juicios de Freitas -el senador corrupto que favorece con una licencia de financiamiento del Banco do Brasil a la primera víctima de la novela - demuestra la crítica radical del escritor al Partido Social-Demócrata, PSD, que según la novela no hizo nada para defender a Getúlio Vargas cuando este sufrió el embate de una parte del Ejército y otras fuerzas sociales en pugna. Para este personaje:

"La traición hacía parte del juego político, máxime ahora, cuando la gran prensa, los militares, los políticos, los estudiantes, las clases productoras, la Iglesia contribuían todos, con ardor exaltado, a la confusión que comenzaba a dominar el país" $(336)^{8}$.

Tal perspectiva del asunto en 1990, solo cinco años después del fin de la dictadura en el país, demuestra la probable cohonestación del escritor con los militares de la época getulista, tal como sugiere Darcy. Pero más allá de esto, esta perspectiva puede evaluarse a partir de la teoría de la anomia social aplicada a la literatura.

8 El subrayado de la palabra confusión es mío. Sustenta el ambiente de anomia en la novela. 


\section{El Varguismo en la política brasilera: "plus ça change plus c'est la même chose"}

Luego de la muerte del presidente Getúlio Vargas, las Fuerzas Armadas conservaron su tutela sobre el Congreso y los partidos políticos fundados por él -Partido Social Democrático (PSD) y el antiguo Partido Trabalhista Brasileiro (PTB)- dominaron la escena política; incluso durante la dictadura (1964-1985) se continuó el modelo económico del intervencionismo de Estado implantado por Vargas que en teoría ofrecía apoyo a los desamparados y excluidos del sistema. Como consecuencia de los movimientos sociales que los medios de comunicación tergiversaron al momento de la muerte de Vargas (de los que da cuenta el texto) se continuaron realmente las políticas del líder populista y se retrasó el presunto golpe de Estado hasta 1964. Este periodo, denominado el Varguismo sin Vargas, fue a su vez una especie de caos histórico, caracterizado, entre otras cosas, por la posesión de ocho presidentes en medio de una confusión social verdaderamente anómica. Con la ayuda del Jefe de la Casa Civil, Golbery do Couto e Silva, Ernesto Geisel, cuarto presidente del régimen (1974-1979), por ejemplo, persistió en las políticas de centralización del poder en el estado militar con poco margen de acción a la iniciativa privada. A continuación:

Pasaron veinte años antes de que un civil volviera a la Presidencia de Brasil. Tancredo Neves, seguidor del "getulismo", que como se recordará fue el Primer Ministro del último gobierno de Vargas y paradójicamente lector nacional de su testamento, fue electo Presidente, lo que demuestra la trascendencia de Getulio Vargas en la política del Brasil y en donde sus palabras "Salgo de la vida para entrar en la historia" adquieren una dimensión temporal. (Sosa de León, párr. 62).

En 1985, en la primera elección indirecta con candidatos civiles para presidente de la República (lo que no se veía desde el golpe militar de 1964), Neves ${ }^{9}$ fue propuesto por una alianza entre varios partidos y elegido como presidente en elecciones directas, tal como lo había sugerido el propio Vargas en los años cuarenta del siglo XX en medio del populismo en ascenso. Este líder murió, no obstante, antes de asumir el

9 Tras el golpe de estado de 1964, se unió a la oposición del Movimiento Democrático Brasileño y en tal militancia fue elegido senador en 1978 y luego gobernador de Minas Gerais en 1982.

114


cargo y en su lugar José Sarney, candidato electo como vicepresidente, se convirtió en presidente constitucional con la intención de seguir las pautas de aquel, es decir, los lineamientos del getulismo. El gobierno de este último (1985-1990) se caracterizó por cierta debilidad política, pues además de no haber reclamado unas nuevas elecciones tras la muerte de Neves sufrió una de las peores crisis económicas del país. A continuación, una nueva constitución que incluía la elección presidencial directa fue promulgada en octubre de 1988 y Fernando Collor de Mello, del Partido de Reconstrucción Nacional, inició su programa anti inflacionista en medio del cual se publica la novela.

Recrear la historia de Getúlio Vargas en 1990 en las condiciones en que lo hace Fonseca (eludiendo la cuestión de Light y exaltando la labor de los militares en la historia brasilera adjudicándoles la autoría de la Carta Testamento) hace parte, entonces, de cierto continuismo político, económico e ideológico del país, sobre todo a la hora de reconocer la labor de los militares al dirigir la república. Al respecto, resulta interesante comparar de nuevo la visión de uno de los personajes de Agosto con la resolución ideológica de la novela: la evaluación de la historia de Alzira, la hija del presidente, personaje literario que en el momento en que las cosas parecen resolverse en su contra dice:

ahora ella tomaba conciencia de la historia como una estúpida sucesión de acontecimientos aleatorios, una intriga inepta e incomprensible de falsedades, inferencias ficticias, ilusiones, poblada de fantasmas. Ahora ella se preguntaba si acaso había dejado de existir aquel otro hombre, cuya memoria había guardado tantos años en su corazón. ¿Era él otro fantasma? ¿Nunca existió? Ese pensamiento le fue tan doloroso e insoportable que por momentos pensó que no resistiría y moriría de dolor allí, en la ventana del palacio de Ingá, en Niterói (420).

La recreación del hecho histórico del presidente Getulio Vargas atrapado en el conflicto de las distintas fuerzas sociales de Brasil se asume aquí desde el punto de vista del impacto psicológico en su hija, es decir, desde una perspectiva íntima del conflicto que se suma a la visión "confusa" del personaje Mattos que da cuenta de la oposición entre ideas y realidad. Esta perspectiva deja incólume al Presidente y entiende la historia como sucesión de hechos azarosos. 
Por el contrario, la realidad que muestra Fonseca en lo que atañe al suicidio de Vargas resulta ser más sistemática y obedece a una intención política mucho más pragmática. El escritor establece en Agosto una teoría que podemos llamar de la necesaria continuidad del poder político conforme a las pautas de Getulio Vargas; es decir, reconoce la vigencia del adagio popular en el cual reflexiona Lomagno en la novela aludiendo a una "máxima perfecta" de los franceses: "plus ça change plus c'est la même chose" (414). Esta lógica histórica es la que describe el escritor y, desde el punto de vista de la historia nacional, la que parece verificarse hasta nuestros días. Desde su punto de vista, pese a las supuestas transformaciones democráticas en el país persiste un Varguismo sin Vargas. A pesar de que en los últimos años de la dictadura se había silenciado la labor social de Vargas (de hecho el populismo, encarnado por él en los años cincuenta del siglo $\mathrm{XX}$, y el comunismo y el socialismo fueron duramente rechazados por los militares), y de que ni su nombre ni su testamento se incluyeron en los estudios de historia como tal, su herencia determina aún la política nacional. La omisión en la novela Agosto del tema del origen de Eletrobrás -la empresa más importante del sector en el país-, así como la atribución de la Carta Testamento de Vargas a los militares pueden tomarse como una lectura indulgente del getulismo y de la dictadura de 1964, lo mismo que de la política contemporánea dominada aún por las pautas de Getulio. Esto que los críticos advierten y juzgan en perjuicio del escritor puede leerse ante todo como su testimonio de que las cosas siempre siguen igual, es decir, que en la historia nacional la clave es el continuismo de las mismas fuerzas políticas desde el año cincuenta y cuatro hasta el noventa del siglo XX. En un contexto de retorno a la democracia y en medio de la creación de Partidos como el Partido de Movimiento Democrático Brasileño, PMDB, Partido de los Trabajadores PT (fundado por Ignacio Lula da Silva), Partido de la Social Democracia Brasileña, PSDB (fundado por Fernando Henrique Cardoso $)^{10}$, la resolución del primer tema de la propiedad sobre la energía eléctrica constituye un ejemplo de esta visión del escritor respecto de la permanencia histórica de las fuerzas económicas, encubiertas por discursos populistas y militaristas a finales del siglo XX y en los albores del siglo XXI. Como quería Getulio y permitieron los militares, Eletrobrás se consolidó como la empresa pública líder del

10 Desde el 2000 aparecen otros como el Partido Verde, el Partido Socialista Libertario, PSOL; el Partido Frente Liberal, PFL, que hoy es Demócrata, DEM.

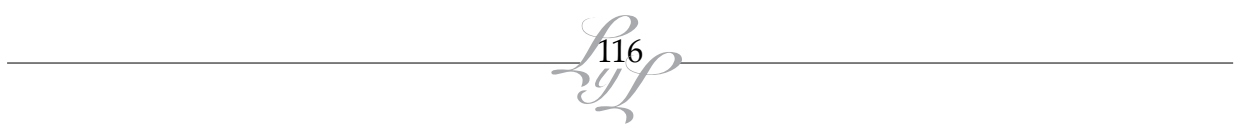


sector; y, a cambio de esto, Light pasó a manos de los mismos militares, tal como ellos lo buscaron (o lo negociaron). Así sucede también con la empresa Cemtex en la novela: a pesar de todo la propiedad se conserva en las mismas manos. Eludir el tema concreto de Light puede confirmar el hecho de que el escritor cuenta la historia conforme a esa lógica señalada como continuismo. Ante la evidencia, mejor callar. Por su parte, en la misma dinámica política de Varguismo sin Vargas, puede afirmarse que Fonseca ofrece una visión posible de la cuestión de la carta testamento del presidente. Así, él la adjudica a un ala de las Fuerzas Armadas que en principio buscan el bien del país, pero que en realidad están cuidando sus intereses económicos, tal como sucedió históricamente. Si poco a poco el tema de la Carta Testamento de Getúlio entró en el dominio de la mitificación y, por lo tanto, en el de la irrevocabilidad ideológica o política (como lo demuestran las reflexiones de Darcy Ribeiro), Fonseca plantea una teoría posible en el marco de los hallazgos de documentos vinculados con esta Carta periódicamente publicados. Desde los años sesenta del siglo XX comenzaron a surgir versiones de distintos críticos en cuanto a la autoría, pues la Carta Testamento se empezó a considerar como una fuente primordial para la comprensión del proceso histórico contemporáneo. Unos conformes con el viejo modelo económico para Brasil; otros con el nuevo; unos pretendiendo la "modernización" económica del país por la vía del neoliberalismo; otros la permanencia de las transformaciones sociales de Getúlio; cada uno a su manera acudía a esa Carta Testamento como referente nacional. Atribuirle una carta a las fuerzas armadas, desde mi punto de vista, tampoco altera el relato histórico de la historia brasilera signada por el Varguismo. Con carta o sin carta los militares continuaron ostentando el poder y permearon la vida política del país de ahí en adelante. Lo importante del asunto es que confirma la tesis del continuismo político, pues ni en la novela ni en la realidad se afecta el discurso que sirve de transfondo a la novela ni a la historia.

Así las cosas, ni en el tema de Eletrobrás ni en el de la Carta, el escritor parece oponerse ideológicamente a esa dinámica histórica derivada del getulismo del siglo XX. Y esto no resulta excepcional sino parte de todo un contexto político e ideológico que se puede verificar en lo que sigue en la historia. Con las pautas del liberalismo, hasta la década del noventa del siglo XX -es decir, con posterioridad a la novela- solo Fernando Henrique Cardoso (del Partido de la Social Democracia Brasileña, PSDB) 
Agosto, de Rubem Fonseca, y el Varguismo en Brasil / Gustavo Forero

buscó lo que puede denominarse el desmonte del Estado protector, pues, en 1994, inició el Plan Real para reestructurar y reducir la deuda externa de Brasil. Desde el 2000, con el Partido Verde, Partido Socialista Libertario, PSOL, el Partido Frente Liberal, PFL, que hoy es Demócrata, DEM, surgió una vuelta evidente a las políticas populistas de los años cincuenta del siglo XX. El triunfo de Luiz Inácio Lula da Silva (2003), de origen sindical (gremio favorecido por Vargas), el éxito político de Leonel Brizola, gobernador del Estado de Rio de Janeiro (1983-1987 y 1991-1994) y líder fundador del Partido Democrático Trabalhista, PDT, o la elección de Dilma Vana Rousseff en 2011, del Partido de los Trabajadores (PT), son solo ejemplos de la vigencia del getulismo en Brasil y la persistencia de los discursos populistas y militaristas derivados de 1964. Como denuncian los autores de Elite da Tropa. Uma guerra tem muitas versões, una novela del 2005, la institución policiva y la propia legislación penal del siglo XXI conservan las pautas del getulismo y de la dictadura y muchos son los "nostálgicos del 64" (95).

\section{Conclusión}

Al final, desde el punto de vista de Rubem Fonseca, es el viejo líder populista de los años treinta del siglo $\mathrm{XX}$, con su trasfondo militar $\mathrm{y}$ autocrático, socialista o democrático, el que sigue determinando la organización del Estado moderno brasileño. Las contradicciones entre las ideas y la realidad siguen en el orden del día (como lo revelan los escándalos de corrupción de los últimos gobiernos). Lejos de proponer una lectura liberal y antimarxista, como esgrimen en su contra los críticos mencionados, se puede afirmar que el escritor da cuenta simplemente de la línea continuista propia de la política brasilera en general, del Varguismo sin Vargas. Reconociendo las virtudes del discurso getulista, elude el tema del campo económico del modelo populista y exalta la bondad de las Fuerzas Armadas en la resolución de los conflictos. El hecho de que el crimen fundamental investigado por Mattos sea de un testaferro de grupos económicos extranjeros no hace más que subrayar una realidad determinada ante todo por las fuerzas del mercado. Tal perspectiva supone una visión ideológica que apenas admite discusión si se mira desde el plano del pragmatismo contemporáneo.

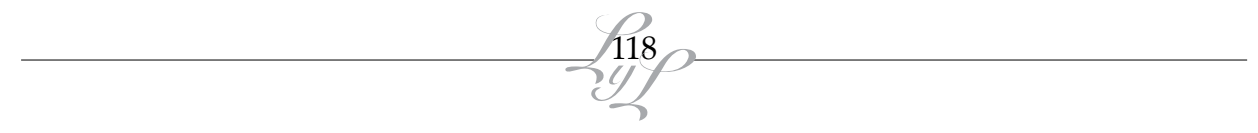




\section{Referencias bibliográficas}

Andrade Pereira, Alinne. "O verdadeiro Mandrake: Rubem Fonseca e sua onipresença invisível (1962-1989)". Tesis. Universidade Federal Fluminense, 2009. Impreso.

Baum, Ana (org). "Carta-testamento". Vargas, Agosto de 54. A história contada pelas ondas do radio. Rio de Janeiro: Garamond, 2004. 227-228. Impreso.

Bittencourt Faraco, Mariana. "A lupa caleidoscópica: o híbrido policialhistórico em Agosto, de Rubem Fonseca, e Santa Evita, de Tomáz Eloy Martínez". Tesis. Pontificia Universidade Católica de Sao Paulo, 2011. Web <http:/ / www.sapientia.pucsp.br/tde_busca/ arquivo.php?codArquivo=13021>

Chaparro Valderrama, Hugo. "Rubem Fonseca: La tradición reinventada". El ojo que piensa. Guadalajara, 2012, pp. 1-14. Impreso.

Fonseca, Rubem. Agosto. Trad. de Álvaro Rodríguez. Bogotá: Norma, 2004.

Forero Quintero, Gustavo. La anomia en la novela de crímenes en Colombia. Bogotá: Siglo del Hombre Editores, 2012. Impreso.

Franken Kurzen, Clemens A. "Rubem Fonseca y su detective-abogado". Taller de Letras 44: 115-127, 2009. Impreso.

Kracauer, Sigfried. La novela policial. Un tratado filosófico. Buenos Aires: Paidós, 2010. Impreso.

Luna, Jayro (Ed.). “Orfeu spam apostilas". Apostila 50 de Lit. brasileira Contemporânea. Web. 8 de abr. de 2013 <http:// www.jayrus.art.br/Apostilas/LiteraturaBrasileira/ Contemporanea/Rubem_Fonseca_Agosto_ resumo_e_comentarios.htm>

Oliva, Osmar Pereira. "Agosto e o discurso marginal fonsequiano". Belo Horizonte 4. dic. 1999: 67-74. Web <http://www. periodicos.letras.ufmg.br/index.php/emtese / article/view/2169> 
Agosto, de Rubem Fonseca, y el Varguismo en Brasil / Gustavo Forero

Ribeiro, Darcy. Aos Trancos e Barrancos. Rio de Janeiro, Guanabara, 1985. Impreso.

Schollhammer, Karl Eric. Ficção brasileira contemporânea. Rio de Janeiro, Civilizacao brasilera, 2009. Impreso.

Silva, Juremir Machado da. Getúlio. Rio de Janeiro, Brazil: Record, 2004. Impreso.

Soares, Jô. O homem que matou Getúlio Vargas. São Paulo: Companhia das Letras, 1998. Impreso.

Soares, Luiz Eduardo et al. Trad. de René Palacios More. Tropa de Elite. Una guerra tiene muchas versiones. Buenos Aires: Marea, 2009.

Tiago Petrik, Malu Porto y João Gabriel de Lima. "Rubem Fonseca - O Seminarista". Revista Bravo! Nov 2009. Web. 16 de abr. de 2013 <http://bravonline.abril.com.br/ materia/rubem-fonseca-seminarista $>$

Vidal, Ariovaldo José. "Rubem Fonseca, o romancista". O Estado de S. Paulo 9 de mar. 1991: 6-7. Impreso.

Waldemer, Thomas. "Rubem Fonseca's Cold Case: The Ephemeral and the Historical in Agosto". Romance Notes Vol. 47. 1. 2006: 33-40. Impreso.

Moniz Bandeira, Luis Alberto. "Getúlio Vargas y el Brasil moderno". La onda digital 2 ene. 2007. Web. 9 de junio de $2013<$ http:/ / www.laondadigital.com/laonda/ laonda/301-400/321/b3.htm>

Zismann, Tatiana. "Getúlio Vargas na ficção: leituras comparadas de um suicídio político". Getúlio Vargas em mundos de ficção: a persona histórica e seus múltiplos ficcionais. Tesis. UFRGS. Web <http:/ / w3.ufsm.br/grpesqla/ revista/dossie10/art_10.php> 